\title{
The relationship between smoking and migraine
}

\author{
G. N. Volans \\ M.B., M.R.C.P. \\ C. M. Castleden \\ M.B., M.R.C.P. \\ Princess Margaret Migraine Clinic, London EC1M 6DX and \\ Departments of Anaesthetics and Clinical Pharmacology, St Bartholomew's Hospital \\ Medical College, London
}

\begin{abstract}
Summary
The theory that smoking could be implicated in the pathogenesis of migraine has been investigated in a prospective survey by the use of a questionnaire and the measurement of carboxyhaemoglobin ( $\mathrm{COHb})$ levels in patients attending a migraine clinic. There was a low incidence of smokers in patients attending for routine consultations and only a small percentage of patients thought that smoking was a cause of their headaches. This percentage was approximately the same both for migraine and for tension headaches. In patients attending with acute headaches, the incidence of smoking was also low, and raised $\mathrm{COHb}$ levels were found only in the smokers, most of whom did not consider smoking a cause of their symptoms. It is concluded that smoking is unlikely to be a factor in the aetiology or the exacerbation of migraine.
\end{abstract}

\section{Introduction}

It has been shown that carbon monoxide intoxication is associated with headache (Forbes, 1970 ) and that inhalation of tobacco smoke (which contains up to $5 \%$ carbon monoxide) (Wynder and Hoffman, 1967) raises the plasma carboxyhaemoglobin level (COHb) (Castleden and Cole, 1974). When this level is raised there is relative anoxia as oxygen has been displaced from haemoglobin (Astrup, 1972). Since anoxia causes vasodilatation it is possible that smoking could be correlated with migraine in certain sensitive individuals.

There are no published reports of smoking as a precipitating factor in migraine but Astrup has shown that smoking or inhalation of carbon monoxide can precipitate the symptoms of mountain sickness, in which headache is a prominent symptom (Astrup, Kjeldsen and Siggaard-Anderson, 1971). Furthermore, headache is common in atopic subjects with tobacco sensitivity (Zussman, 1970) and smoking was associated with increased menstrual pain in a group of subjects in whom there was also

Correspondence: Dr G. N. Volans, Poisons Unit, New Cross Hospital, London. a high incidence of menstrual headaches (Procope 3 and Timonen, 1971).

Our clinical experience suggested that some migraine patients associated smoking with either the onset or exacerbation of their symptoms and $\%$ there also appeared to be a low incidence of smoking $\circ$ in these individuals. We therefore undertook $\mathrm{a}$ prospective survey to determine the incidence of smoking in migraine patients and to ascertain $\mathbb{O}$ whether smoking and/or elevated $\mathrm{COHb}$ levels could be implicated in the pathogenesis of migraine or other headaches.

\section{Methods}

The study was in two parts:

(a) One hundred consecutive new patients attending a migraine clinic for routine consultations with $\overline{0}$ one physician (G.N.V.) answered a short question- $\stackrel{0}{\circ}$ naire, which was incorporated into the customary $\stackrel{\odot}{\complement}$ interview, on their smoking habits.

(b) Fifty patients who attended the same clinic 3 for treatment of acute headaches were asked the same questions. In addition, the duration of symptoms before arrival at the clinic and the time of the last cigarette were recorded. Before the patient 3 . received treatment, a venous blood specimen was collected into a heparinized syringe, capped, and analysed for $\mathrm{COHb}$ on the same day by means of a $O$ CO-oximeter (Instrumentation Laboratories-model $₹$ 182). Cross checks for accuracy were made on each 옥 batch of samples by the Commins and Lawther $D$ method.

All diagnoses of migraine conformed to the classification of the World Federation of Neurology (1970).

\section{Results}

\section{Routine consultations}

Table 1 shows that of one hundred new patients (twenty-four male, seventy-six female; mean age $\stackrel{\mathcal{C}}{+}$ \pm s.d. $=40 \pm 12$ years), twenty were currently smokers 0 whilst twenty-four were ex-smokers. Nine patients 
TABLE 1. The claimed relationship of smoking habits to headaches in 100 consecutive new patients attending a migraine clinic

\begin{tabular}{|c|c|c|c|c|}
\hline \multirow[b]{2}{*}{$\begin{array}{c}\text { Smoking } \\
\text { habits }\end{array}$} & \multirow[b]{2}{*}{ Sex } & \multicolumn{3}{|c|}{$\begin{array}{l}\text { Effect of smoking or } \\
\text { smoke on headaches }\end{array}$} \\
\hline & & $\begin{array}{c}\text { Cause } \\
\text { headaches }\end{array}$ & $\begin{array}{l}\text { Increase } \\
\text { severity } \\
\text { of headaches }\end{array}$ & $\begin{array}{c}\text { No effect } \\
\text { on } \\
\text { headaches }\end{array}$ \\
\hline Smokers (20) & $\begin{array}{l}\text { M } 12 \\
\text { F } 8\end{array}$ & $\left.\begin{array}{l}2 \\
3\end{array}\right\} 5$ & $\left.\begin{array}{l}4 \\
5\end{array}\right\}$ & $\left.\begin{array}{l}8 \\
3\end{array}\right\} 11$ \\
\hline $\begin{array}{l}\text { Ex-smokers } \\
\text { (24) }\end{array}$ & $\begin{array}{ll}\text { M } & 10 \\
\text { F } & 14\end{array}$ & $\left.\begin{array}{l}2 \\
2\end{array}\right\} 4$ & $\left.\begin{array}{l}2 \\
5\end{array}\right\} 7$ & $\left.\begin{array}{l}8 \\
9\end{array}\right\} 17$ \\
\hline $\begin{array}{l}\text { Never } \\
\text { smoked (56) }\end{array}$ & $\begin{array}{lr}\text { M } & 2 \\
\text { F } & 54\end{array}$ & - & $\left.\begin{array}{r}0 \\
17\end{array}\right\} 17$ & $\left.\begin{array}{r}2 \\
37\end{array}\right\} 39$ \\
\hline Totals (100) & $\begin{array}{l}\text { M } 24 \\
\text { F } 76\end{array}$ & $\left.\begin{array}{l}4 \\
5\end{array}\right\} 9$ & $\left.\begin{array}{r}6 \\
27\end{array}\right\} 33$ & $\left.\begin{array}{l}18 \\
49\end{array}\right\} 67$ \\
\hline
\end{tabular}

thought that smoking actually caused headaches. Only one gave up smoking because of this, and five of the nine are still currently smoking. Thirty-three patients reported that smoking or smoke exacerbated their headaches. Seventeen of these were women who had never smoked. Smoking or smoke was reported as a possible cause or exacerbating factor in approximately equal percentages of patients whether the headache was migraine or tension headache (Table 2).

\section{Acute headaches}

Of fifty patients (twenty male, thirty female; mean age \pm s.d. $=35 \pm 12$ years), seventeen were currently smokers (eight male, nine female). Only eleven patients thought that active or passive smoking was a factor in the causation or exacerbation of their headaches and, of these, six had never actively smoked.

The mean $\mathrm{COHb}$ level of the smokers was $4.9 \%$ (range $0.1-7.9 \%$ ) and of the non-smokers was $1.9 \%$ (range $0.9-3.8 \%$ ). The highest $\mathrm{COHb}$ levels were

TABLE 2. The relationship of the claimed effects of smoking or smoke on headaches to the type of headache in 100 consecutive new patients attending a migraine clinic

\begin{tabular}{|c|c|c|c|}
\hline Diagnosis & Sex & $\begin{array}{l}\text { Effect of s } \\
\text { smoke on } \\
\text { Causes or } \\
\text { increases } \\
\text { headaches }\end{array}$ & $\begin{array}{c}\text { moking or } \\
\text { headaches } \\
\text { No effect } \\
\text { on } \\
\text { headaches }\end{array}$ \\
\hline Migraine & $\begin{array}{ll}\left.\begin{array}{ll}M & 13 \\
F & 66\end{array}\right\} 79\end{array}$ & $\left.\begin{array}{r}2 \\
24\end{array}\right\} 26$ & $\left.\begin{array}{l}11 \\
42\end{array}\right\} 53$ \\
\hline $\begin{array}{l}\text { Tension } \\
\text { headache }\end{array}$ & $\left.\begin{array}{lr}\text { M } & 7 \\
\text { F } & 10\end{array}\right\} 17$ & $\left.\begin{array}{l}3 \\
3\end{array}\right\} 6$ & $\left.\begin{array}{l}4 \\
7\end{array}\right\} 11$ \\
\hline $\begin{array}{l}\text { Migrainous } \\
\text { neuralgia }\end{array}$ & $\left.\begin{array}{ll}M & 4 \\
F & 0\end{array}\right\} 4$ & $\left.\begin{array}{l}1 \\
0\end{array}\right\} 1$ & $\left.\begin{array}{l}3 \\
0\end{array}\right\} 3$ \\
\hline Totals & $\left.\begin{array}{l}\text { M } 24 \\
\text { F } 76\end{array}\right\} 100$ & $\left.\begin{array}{r}6 \\
27\end{array}\right\} 33$ & $\left.\begin{array}{l}18 \\
49\end{array}\right\} 67$ \\
\hline
\end{tabular}

found in the patients who had smoked most recently but there was no obvious correlation between the duration of the attack and $\mathrm{COHb}$ levels.

\section{Discussion}

The patients in this study were divided into two groups, the 'cold cases' attending for consultation at a time when they were symptom-free and the 'acute cases' who attended for treatment during migraine attacks. If the theory that smoking caused headaches was correct it would have been expected there to be few smokers amongst the cold cases and both a higher incidence of smokers and a high mean $\mathrm{COHb}$ level in the acute cases. In fact, a low incidence of smoking in both groups of patients was found. Even though the majority of patients attending for consultation were female $(76 \%)$, there were still far fewer smokers among them (20\%) than it has been reported from random populations matched for age and sex in America (38\%) or in Britain (50\%) (Report of Surgeon General, 1971; Report of Royal College of Physicians, 1971). Furthermore, $24 \%$ of the subjects were ex-smokers whereas in an American survey only $13-15 \%$ had given up cigarette smoking (Report of Surgeon General, 1971). Hence, the incidence of smoking in the patients of this study was less than half that of the general population, and approximately twice as many patients had given up smoking than could be expected in the population at large.

If the cold case study suggests a correlation between smoking and migraine, the acute case study does not bear this out. Although $34 \%$ of subjects presenting with acute migraine had a raised $\mathrm{COHb}$ level indicating recent tobacco smoke inhalation, $66 \%$ did not, and their symptoms were no different from those of the smokers. As a group, the acute patients had a very low incidence of smoking (34\%) when compared to other groups of workers in the City of London (Castleden and Cole, 1975). Random checks on the COHb level of manual and office workers showed that $68 \%$ had a raised $\mathrm{COHb}$ level, whilst the incidence in blood donors-a group with a high proportion of nonsmokers-was $44 \%$ (Castleden and Cole, 1975).

Hence, although fewer migraine patients smoke and more give up smoking than in the general population, smoking could not be implicated in the majority of patients presenting with acute headaches at the migraine clinic. Furthermore, approximately $50 \%$ of the forty-four subjects, who said that smoking was involved in exacerbating their headache, had never actively smoked and therefore must have been referring to passive smoking. By using extreme conditions, it has been shown that it is possible to increase the $\mathrm{COHb}$ level of passive smokers by only $1 \%$ over a period of $78 \mathrm{~min}$ (Russell, Cole and 
Brown, 1973). It is, therefore, most unlikely that a constituent of cigarette smoking was involved in the headaches of the patients who had never smoked. From this study it is concluded that the theory of an association between smoking and migraine has not been proved and that no evidence was found to suggest that active or passive smoking is a factor in the aetiology of migraine.

\section{Acknowledgments}

We would like to thank Dr Marcia Wilkinson, Director of the Princess Margaret Migraine Clinic, and Dr P. V. Cole, Consultant Anaesthetist in the Department of Anaesthetics, St Bartholomew's Hospital, for their advice and helpful criticism.

\section{References}

AsTRUP, P. (1972) Some physiological and pathological effects of moderate carbon monoxide exposure. British Medical Journal, 4, 447.

AstruP, P., KJeldSEN, K. \& SiggaArd-Anderson, J. (1971) Carbon monoxide induced mountain sickness provoked by tobacco smoking. Lancet, $\mathbf{i}, \mathbf{7 8 1}$.
Castleden, C.M. \& Cole, P.V. (1974) Variations in carboxy haemoglobin levels in smokers. British Medical Journal, 4 736.

Castleden, C.M. \& Cole, P.V. (1975) Carboxyhaemoglobin ${ }^{\complement}$ levels of smokers and non-smokers working in the City of London. British Journal of Industrial Medicine, 32, 115 . की

FORBES, W.H. (1970) A carbon monoxide uptake via the lungs. Annals of the New York Academy of Sciences, 174등 72.

Procope, B.J. \& Timonen, S. (1971) The premenstrua syndrome in relation to sport, gymnastics and smoking Acta obstetrica gynecologica scandinavica, 9, (Suppl. 9), 77,

RePort of the Royal College of Physicians. Smoking and Health Now. London (1971).

RePORT OF THE SURgeon General. Health Consequences of Smoking. U.S.A. (1971).

Russell, M.A.H., Cole, P.V. \& Brown, E. (1973) Absorpळ tion by non-smokers of carbon monoxide from room ai polluted by tobacco smoke. Lancet, i, 576.

WORLd Federation of Neurology Research Group on. Migraine AND HEadaChe (1970) Definition of migraine $N$ In: Background to Migraine (Ed. by A. L. Cochrane) pp. 181-182. London, Heinemann.

WYNDER, E.L. \& HoFFMAN, D. (1967) Tobacco and Tobacco Smoke-Studies in Experimental Carcinogenesis. New York, Academic Press.

Z.USSMAN, B.M. (1970) Tobacco sensitivity in the allergic patient. Annals of Allergy, 28, 371. 